Review Article

\title{
Preliminary Discussion on Comprehensive Research Method for Rock Burst in Coal Mine Based on Newton's Second Law
}

\author{
Jianping Zuo $\mathbb{D}^{1,2}$, Hongqiang Song $\mathbb{D}^{1},{ }^{1}$ Yunqian Jiang $\mathbb{D}^{1},{ }^{1}$ Shankun Zhao $\mathbb{D}^{3},{ }^{3}$ Meilu Yu $\mathbb{D}^{1}$, \\ and Liyun Li $\mathbb{D}^{1}$ \\ ${ }^{1}$ School of Mechanics and Civil Engineering, China University of Mining and Technology (Beijing), Beijing 100083, China \\ ${ }^{2}$ State Key Laboratory of Coal Resources and Safe Mining, China University of Mining and Technology (Beijing), \\ Beijing 100083, China \\ ${ }^{3}$ Mine Safety Technology Branch, China Coal Research Institute, Beijing 100013, China
}

Correspondence should be addressed to Jianping Zuo; zjp@cumtb.edu.cn and Hongqiang Song; shqmfyx@163.com

Received 27 March 2020; Revised 23 August 2020; Accepted 26 September 2020; Published 13 October 2020

Academic Editor: Fabio Rizzo

Copyright (C) 2020 Jianping Zuo et al. This is an open access article distributed under the Creative Commons Attribution License, which permits unrestricted use, distribution, and reproduction in any medium, provided the original work is properly cited.

Rock burst is one of the major dynamic disasters that directly threaten production safety in coal mines. According to the current research, the occurrence of rock burst can be described by the generalized Newton's second law with three elements which are research object, force condition, and motion state. These three elements refer to the coal and rock mass in the mining area, concentrated static and dynamic loads, and dynamic instability of surrounding rock, respectively. On this basis, a comprehensive rock burst research method involving the three elements of Newton's second law was proposed, which especially focuses on the investigation into geological conditions of mining areas. The research procedure of this method specifically includes the detailed exploration of engineering geological bodies, the classification and stability evaluation of surrounding rock, the measurement and inversion of in situ stress, the evolution analysis of mining-induced stress field, energy field, and fracture field, the study of multiscale failure mechanism of coal and rock mass, the establishment of theoretical failure model of coal and rock mass, the realtime monitoring and warning in potentially dangerous areas, and the reasonable prevention and control in key risk zones. As a preliminary discussion, the significant research progress in each aspect mentioned above has been reviewed and the feasible research directions of rock burst are presented in this paper.

\section{Introduction}

With the increase of mining depth, rock burst has been recognized as one of the typical dynamic disasters for underground coal mining. As rock burst represents a sudden and violent failure in coal mass and it dynamically releases the elastic energy accumulated in coal and rock mass, significant damages and serious injuries are caused on mining equipment and miners, respectively [1]. China is relatively rich in coal resources, and the conditions of coal seam occurrence vary greatly. Because the coal seams are often located in the junction of complex tectonic plates and due to the variation in coal seam thickness and dip angle, multiple mining hazards are frequently induced [2]. Nowadays, nearly 50 coal mines in China have exceeded $1000 \mathrm{~m}$ mining depth as the shallow coal resources are almost exhausted. As the mining depth increases, the rock burst disasters are extremely serious. The number of rock burst mines in China has greatly increased from only 32 in year 1985 to 167 in year 2016 [3]. Meanwhile, both rock burst frequency and magnitude also present a remarkable increasing trend. For instance, severe rock burst disasters occurred twice in Qianqiu coal mine in 2008 and 2011. Yuncheng coal mine in Shandong also suffered a major rock burst disaster on October 20, 2018, resulting in 21 deaths. In recent years, the new features of rock burst disasters have emerged. One is that rock burst also occurs in shallow mine mining. For example, the northern mining area of Wudong coal mine in Xinjiang experienced a rock burst at a burial depth of $157 \mathrm{~m}$ on March 24, 2011, and it caused 1 death and 2 injuries. The 
other is the increase of secondary catastrophes induced by rock burst, such as the Sunjiawan coal mine gas explosion which occurred in 2005. Figure 1 presents the damages of rock burst disasters where Figure 1(a) specifically shows the rock burst damage in the 3316\# air roadway in Sunjiawan coal mine known as " $2 \cdot 14$ " disaster site. A large area of floor was heaved and the scraper conveyor was buckled. From the analysis of geological structure, the reason for such a great burst is that the lateral side of $3316 \#$ air roadway passes a transition zone where tectonic plate changes from anticline to syncline. Figure 1(b) presents the 2103\# belt roadway site of the " $2 \cdot 28$ " accident in Gucheng coal mine, and it is clear that the roadway was badly deformed due to the strong burst of coal mass. From the perspective of occurrence environment, the coal seam is buried up to $1100 \mathrm{~m}$, and the overburden contains multilayered thick and hard sandstone, which bring about high stress in surrounding rock. Coupled with the strong burst liability of coal seam, a great amount of energy is easy to be released abruptly under the influence of mining disturbance.

Rock burst has always been a hot issue in coal mining and other geotechnical engineering. Scholars worldwide have put forward some mechanisms of rock burst [4, 5], developed various methods for monitoring and warning $[6,7]$, and conducted a series of measures to prevent rock burst $[8,9]$. However, due to the limitation of current rock burst research, the diversity of mine types, and the complex geological conditions, rock burst disasters still arise constantly in China. Previously, research studies on rock burst mainly focused on mechanism, monitoring, and control, whereas the differences in the geological conditions between mines were neglected, which may largely affect the rock burst mechanism. Therefore, if no more attention is paid to the study of geological conditions such as structural features and stress level, it will lead to misjudgement of rock burst mechanism and ineffective prevention and control. Consequently, the research on rock burst should form a system including not only failure mechanism, monitoring, and control but also geological conditions. Based on the concept of Newton's second law, a comprehensive research method for rock burst is proposed with the research object, force condition, and motion state. In addition, the research progress of each aspect in recent years is collected and summarized. Finally, the future research area is determined with respect to the possible improvement in coal mine safety production.

\section{Discussion on the Research Procedure of Rock Burst Based on Newton's Second Law}

The "three-factor" mechanism [10], which includes the intrinsic factor (burst liability), structure factor, and stress factor, has been widely used to explain the occurrence of rock burst. Burst liability is an index that characterizes whether coal or rock has the property of burst failure, and the structure factor refers to the structural characteristics of coal and rock mass, such as layer structure, thin soft interlayer, fault, and coal seam thickness change zone. The above two factors belong to the inherent properties of coal and rock mass. The stress factor mainly depends on the in situ stress and mining-induced stress, which are closely related to mining activities. Compared with intrinsic and stress factors, the structure factor is nonquantifiable, but the structural properties of coal and rock mass can still be obtained by detection technology.

Newton's second law in classical mechanics, $\mathbf{F}=m$ a, interprets the relationship between the motion state of a macroscopic object and the subjected forces, indicating that the motion of an object involves three elements, i.e., research object, force condition, and motion state. The essence of rock burst is the dynamic instability process of coal and rock mass subjected to highly concentrated loads. According to the concept of Newton's second law, the research object, force condition, and motion state during rock burst refer to the coal and rock mass in the mining area, concentrated static and dynamic loads [11], and dynamic instability of surrounding rock, respectively. For the mechanism of "three factors," both burst liability and structure factor belong to the inherent property studies of research object, and the stress factor corresponds to force condition. Therefore, the occurrence of rock burst can be described by the generalized Newton's second law. It can be explained that coal and rock mass are in stress equilibrium state without concentrated load induced by mining, and then mining activities disturb this equilibrium state and cause a concentrated generalized force $\mathbf{F}$ and a corresponding generalized initial acceleration a. Figure 2 describes the relation between generalized initial acceleration of surrounding rock and its instability form. When the generalized initial acceleration is very small, the quasistatic failure occurs and it is in the controllable range of supporting system. However, when the generalized initial acceleration increases to a certain critical value, sudden and violent surrounding rock deformation will occur, and the ultimate bearing capacity of the supporting system will be exceeded, and hence rock burst and other dynamic disasters will be triggered.

Based on the above discussion, rock burst research should form a systematic procedure that includes the three elements of Newton's second law, namely, research object, force condition, and motion state. As shown in Figure 3, the research procedure of rock burst comprises five main components, in which the studies on research object, force condition, and motion state are the significant foundation of rock burst research. For the research object, the geological structures of the mining area can be firstly determined by the detailed exploration of engineering geological bodies. Then, it is necessary to evaluate the stability of roadway surrounding rock and coalface roof. Based on the above studies, the structure factor in the "three-factor" mechanism will be obtained. Regarding the force condition, the measurement and inversion calculation of in situ stress should be carried out to estimate the regional geostress distribution without mining disturbance. After mining, it is crucial to obtain the evolution laws of mining-induced stress, energy, and fracture fields in the mining area. These studies can be used to determine the stress factor of the "three-factor" mechanism. In the aspect of motion state, the multiscale burst failure mechanisms of coal and rock mass need to be investigated in 


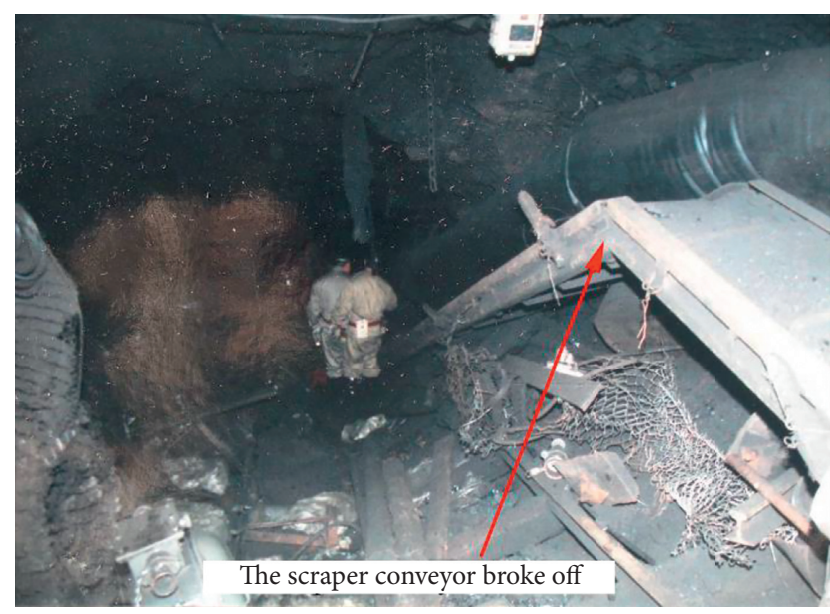

(a)

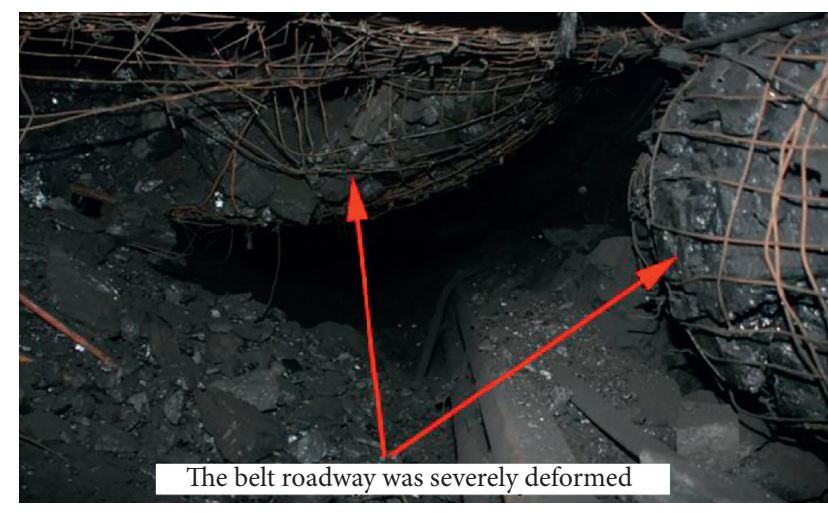

(b)

FIGURE 1: Site photos of rock burst disasters in coal mines. (a) The 3316\# air roadway in Sunjiawan coal mine. (b) The 2103\# belt roadway in Gucheng coal mine. Note: the two photos in Figure 1 are obtained from the following web page-https://max.book118.com/html/2018/ $1112 / 7010162164001156 . s h t m$.

Instability forms of surrounding rock

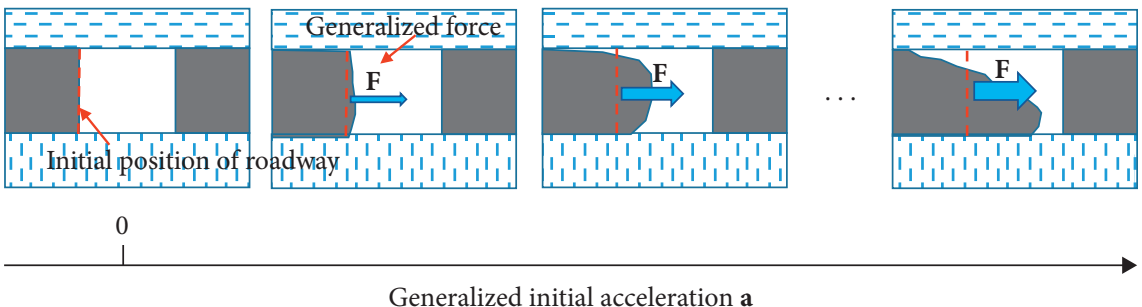

Generalized initial acceleration a

FiguRE 2: Schematic of the relation between generalized initial acceleration of surrounding rock and its instability form.

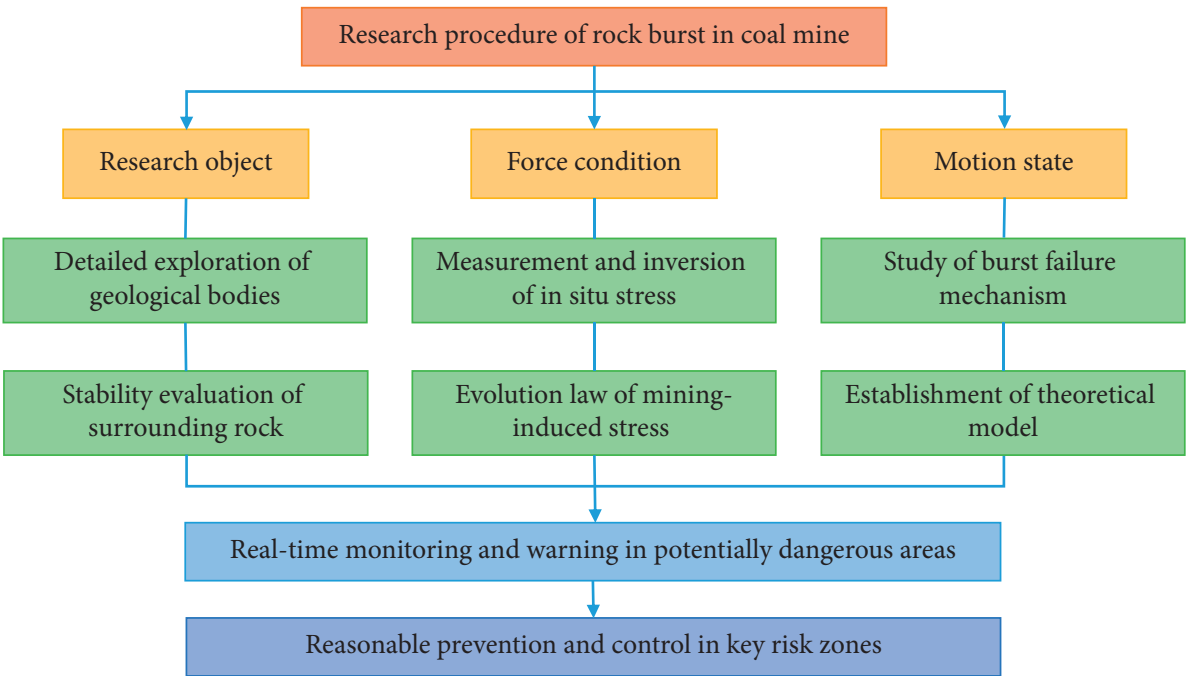

FIGURE 3: Research procedure of rock burst involving the three elements of Newton's second law. 
depth based on the theoretical analysis, numerical simulation, laboratorial experiment, and site testing. Besides, the corresponding theoretical models should also be established to describe the instability process of coal and rock mass. Through the aforementioned experimental studies, the intrinsic factor in the "three-factor" mechanism can be determined. Finally, based on the preceding research studies on the stability of surrounding rock and the burst failure mechanism of coal and rock mass, real-time monitoring and warning should be carried out in potentially dangerous areas and targeted prevention and control measures need to be adopted for the key risk zones at the same time.

\section{Research Object in the Mining Area}

3.1. Detailed Exploration of Engineering Geological Bodies. Rock burst in coal mine has been classified from different aspects, as shown in Table 1. It can be seen that the geological structure is regarded as an important factor in inducing rock burst. In addition, the coal mining practices revealed that rock burst induced by geological structures (fault, fold, collapse column, etc.) is more violent and causes more serious damage. Therefore, finding out the geological conditions of mining areas is the prerequisite of rock burst research.

Along with the continuous development of geological detection technology, drilling prospecting, geophysical prospecting, and geochemical prospecting have become the three major directions. Geophysical prospecting methods including seismic exploration, direct current electric method, transient electromagnetic method, and groundpenetrating radar have been widely utilized, and these methods have the advantages of noncontact, nondestructive detection, convenience, and rapidity. Three-dimensional seismic prospecting has become the preferred technology for detecting hidden geological structures and unfavourable geological bodies in coal mining areas with high resolution detection outcomes [15]. Underground channel wave seismic detection is extensively used for the detailed exploration of internal structures such as minor faults, coal seam splitting, and thinning zone, with the superiority of long detection range (up to 300 times of coal thickness) and high accuracy [16]. Based on the difference of rock conductivity, the direct current method plays an important role in detecting water-rich structures ahead of the heading face due to its simple principle [17]. The transient electromagnetic method is well adopted to detect the water-bearing faults and fissure zones in coal mines owing to its high sensitivity to low resistance geological bodies [18]. Ground-penetrating radar is gradually adopted to detect the close-range geological structures in front of the working face due to its high detection precision and flexibility [19]. China University of Mining and Technology (Beijing) has developed underground explosion-proof ground-penetrating radar with a $50 \mathrm{~m}$ effective detection range, and it has greatly promoted the engineering application of ground-penetrating radar. Figure 4 illustrates the plane and spatial distribution of two collapse columns at Xieqiao coal mine obtained by utilizing the high-precision 3D seismic technology. It has clearly presented that these two collapse columns are in irregular inverse cone shapes and that the working face 13118 will pass through these two collapse columns. After knowing such a geological condition, numerical simulation was adopted and it indicated that the sudden stress release may trigger rock burst in the failure subsidence stage [20].

\subsection{Classification and Stability Evaluation of Surrounding} Rock. Rock burst is a dynamic instability form of surrounding rock, and it severely affects the safety in coal mine production. Therefore, it is of great significance to correctly evaluate the stability of surrounding rock. In general, surrounding rock stability is affected by geological factors and engineering factors. Geological factors include lithology and structure of surrounding rock, geostress, groundwater, and other geological conditions. Engineering factors mainly refer to orientation and section form of roadway, construction method, and support mode. Recently, a large number of classification methods for engineering rock mass have been proposed, in which the rock quality designation (RQD) method [21], rock mass rating (RMR) method [22], Q system method [23], and "Standard for engineering classification of rock mass" (GB50218-2014) [24] are widely applied. Based on the geological characteristics of underground mines and stability states of surrounding rock after mining, the roadway surrounding rock is distinguished by five different types in China, namely, stable rock mass, comparatively stable rock mass, generally stable rock mass, comparatively instable rock mass, and instable rock mass.

The mining practice shows that roof hazards account for a considerable proportion in coal mine accidents and a sudden roof caving often leads to severe rock burst disaster. China issued the coal industry standard "Roof Stability Classification of Coalface in Gently Inclined Coal Seams" in 1996, which classifies immediate roof into four types according to several indices, such as the uniaxial compressive strength of rock, layer thickness, lithology, development characteristic of joint, and first caving span of immediate roof. The stability classification method for immediate roof is shown in Table 2.

The factors that affect surrounding rock stability are always uncertain and their influence mechanisms are not completely studied, which make difficulties for quantitative research. As a result, the multi-index classification method possesses certain subjectivity. Along with the recent development of testing techniques and computing technology, more investigations are implemented based on a research approach that combines both multi-index evaluation and mathematical approaches such as fuzzy mathematics, neural network, multivariate statistical analysis, and grey theory [26]. These methods can quantitatively determine the values of evaluation indices, thus making the classification results more reasonable and reliable.

\section{Force Condition in the Mining Area}

4.1. Measurement and Inversion of In Situ Stress. The in situ stress is the basic force causing roadway and stope failure, 
TABLE 1: Classification of rock burst in coal mine.

\begin{tabular}{lc}
\hline Classification basis & Types of rock burst \\
\hline Stress source & Gravity type, structure type, and gravity-structure type \\
Energy source & Coal mass compressible type, roof crack type, and fault dislocation type [12] \\
Seismic source and pressure appearance & Mining type (pressure type, burst type, and burst-pressure type) and structure type [13] \\
Instability form & Material failure type, slipping-dislocation type, and structure instability type [14] \\
\hline
\end{tabular}

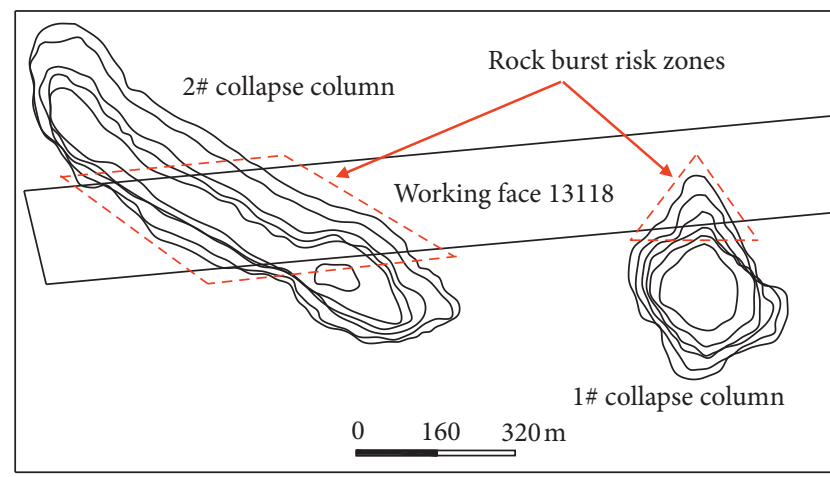

(a)

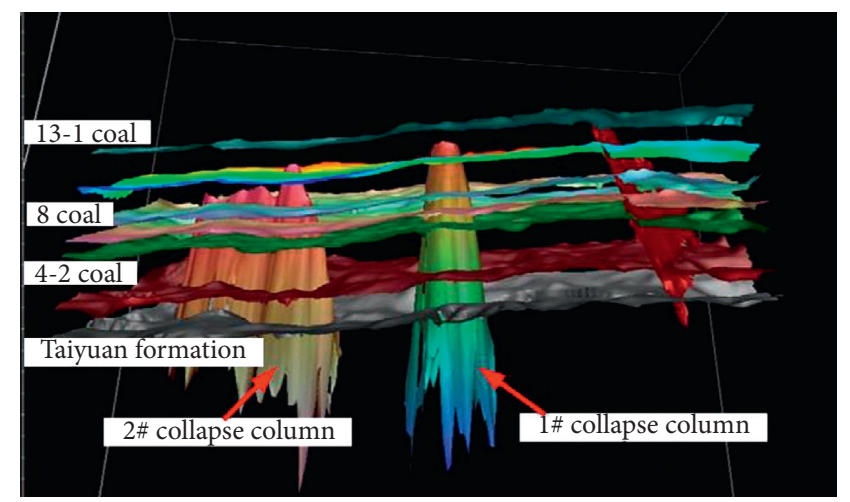

(b)

FIgURE 4: Distributions of collapse columns at the Xieqiao coal mine [20]. (a) Plane distribution. (b) Stereographic map.

TABle 2: Classification system for immediate roof [25].

\begin{tabular}{|c|c|c|c|c|c|}
\hline \multirow{3}{*}{ Classification } & \multicolumn{2}{|r|}{$\mathrm{I}$} & \multirow{3}{*}{$\begin{array}{c}\text { II } \\
\text { Moderately stable }\end{array}$} & \multirow{3}{*}{$\begin{array}{c}\text { III } \\
\text { Stable }\end{array}$} & \multirow{3}{*}{$\begin{array}{c}\text { IV } \\
\text { Very stable } \\
\end{array}$} \\
\hline & Ia & $\mathrm{Ib}$ & & & \\
\hline & & Instable & & & \\
\hline $\begin{array}{l}\text { Lithology and } \\
\text { structural } \\
\text { property }\end{array}$ & $\begin{array}{l}\text { Mudstone, shale; } \\
\text { developed joints } \\
\text { and fissures }\end{array}$ & $\begin{array}{c}\text { Mudstone, carbonaceous } \\
\text { mudstone; relatively } \\
\text { developed joints and } \\
\text { fissures }\end{array}$ & $\begin{array}{c}\text { Compact mudstone, } \\
\text { siltstone, sandy mudstone; } \\
\text { undeveloped joints and } \\
\text { fissures }\end{array}$ & $\begin{array}{c}\text { Sandstone, } \\
\text { limestone; few } \\
\text { joints and fissures }\end{array}$ & $\begin{array}{l}\text { Compact sandstone, } \\
\text { limestone; extremely } \\
\text { few joints and fissures }\end{array}$ \\
\hline$l_{\mathrm{r}}$ & $\leq 4$ & $4-8$ & $8-18$ & $18-28$ & $28-50$ \\
\hline$R_{\mathrm{c}}$ & $27.94 \pm 10.75$ & $36 \pm 25.75$ & $46.3 \pm 20$ & $65.3 \pm 33.7$ & $89.4 \pm 32.6$ \\
\hline$h_{0}$ & $0.26 \pm 0.125$ & $0.285 \pm 0.13$ & $0.51 \pm 0.355$ & $0.675 \pm 0.34$ & $0.72 \pm 0.34$ \\
\hline$R_{\mathrm{c}} \cdot h_{0}$ & $<7.5$ & $2.9-11.4$ & $7.8-29.1$ & $33-104$ & $45.5-139.4$ \\
\hline$C_{\mathrm{z}}$ & $0.163 \pm 0.064$ & $0.273 \pm 0.09$ & $0.30 \pm 0.12$ & $0.43 \pm 0.157$ & $0.48 \pm 0.11$ \\
\hline
\end{tabular}

Note. $l_{\mathrm{r}}$ : first caving span of immediate roof; $R_{\mathrm{c}}$ : uniaxial compressive strength; $h_{0}$ : layer thickness; $R_{\mathrm{c}} \cdot h_{0}$ : equivalent bending capacity; $C_{\mathrm{z}}$ : comprehensive weakening constant.

and its size and direction have significant influences on the stress state of surrounding rock [27]. Self-weight stress and structure stress are the two main types of in situ stress, where horizontal structure stress is the major force source of rock burst occurring in the geological structure region. With the increasing mining depth, the self-weight stress increases gradually and the further developed geological structure makes the structure stress field more complex. Thus, the possibilities of having destructive rock burst are positively correlated to the mining depth [28].

A variety of in situ stress measurement methods have been studied for years [29]. According to the measuring principles, these can be classified into mechanical methods and geophysical methods. Mechanical methods focus on the stress, strain, or deformation of rock mass, such as the flat jack method, stress restoration method, stress relief method, and hydraulic fracturing method, whereas geophysical methods follow the basis of the variation of elastic wave, acoustic emission, resistivity, and electromagnetism in rock mass, such as the Kaiser effect method and atomic magnetic resonance method. In practice, the stress relief method and hydraulic fracturing method are extensively used in coal mines. The former is an indirect measurement, while the latter is a direct measurement. Hollow inclusion strain cell is mainly adopted in the stress relief method, which can get the three-dimensional stresses by drilling only once. Therefore, it is considered to be one of the best in situ stress measurement techniques because of its installation simplicity, high accuracy, and reliable test results [30]. Although the hydraulic fracturing method does not require elastic 
parameter measurements in advance and complex technology and is less affected by the environment, it is still mainly used for ground deep well measurement due to its huge equipment and large borehole diameter [31]. In order to achieve rapid in situ stress measurement in coal mine, a small borehole hydrofracturing device was developed, and it has been extensively applied in the mine roadways [32].

Due to the limitation of objective conditions, the initial stress field can only be estimated by certain assumptions on the basis of local stress data. At present, there are three common methods for obtaining the geostress field. The first method is to estimate the simple stress field according to certain theories, including the self-weight stress estimation method, Heim's law, and lateral pressure coefficient method. These methods are relatively simple and have been adopted in some small-scale projects. The second method assumes that the initial stress field fits a certain distribution function, and hence the numerical methods of fitting or regression are used to make the calculated value approximate the measured one. Distribution function methods such as the stress function method and the boundary load adjustment method are suitable for the situation when the regional in situ stress measurement data are sufficient. The third method indirectly uses the measured displacement value that considers the excavation disturbance to estimate the initial stress field, namely, displacement back analysis method. This method is appropriate for the study areas which lack in situ stress data but have effective deformation records. Currently, with the advancement of computing technology, nonlinear algorithms such as the neural network method, genetic algorithm, and grey control theory have been introduced into the calculation and inversion of initial stress field, and these methods have significantly improved the calculation efficiency and accuracy [33].

\subsection{Evolution Laws of Mining-Induced Stress Field, Energy} Field, and Fracture Field. Mining activities break the balance state kept by surrounding rock of roadway and coalface, resulting in the stress redistribution as well as the variation in energy field and fracture field. In general, once the elastic energy accumulated in the stress concentration area is released, the possibilities of having serious rock burst are increased. Consequently, analysing and determining the evolution of the stress, energy, and fracture fields in the mining area will not only contribute to the understanding of rock burst mechanism but also provide some guidance on rock burst monitoring.

Regarding the theoretical studies of overlying strata stress field, scholars around the world have put forward various hypotheses such as cantilever beam, preformed fracture, and hinge rock block. The theory of voussoir beam [34] and the theory of transferring rock beam [35] proposed in the 1980s have laid the theoretical foundation of mine pressure in China. The stress field ahead of the working face has also been widely studied. For example, $\mathrm{Xu}$ et al. [36] measured the variation of mining-induced abutment pressure in a fully mechanized working face by using a selfdeveloped stress real-time monitoring system as well as electromagnetic radiation technology. By considering the cutting face where dynamic disasters occurred as prototype, Yang et al. [37] established a numerical model through FLAC3D and analysed the evolution laws of mining stress field. As a result, the characteristics of the peak stress concentration factors of vertical and horizontal stress ahead of the working face, the influence distance of stress, and the distance from peak stress to coal wall were obtained through these studies mentioned above.

With respect to the mining-induced energy field, Li et al. [38] believed that the area in which compression and elastic rebound occur after the hard roof fracturing is the seismic source based on the laws of energy accumulation and dissipation during the first fracture of hard roof. Wang and Park [39] investigated the accumulation characteristics of strain energy around the mining pits with three-dimensional FEM simulation. An analytical solution of mining-induced energy redistribution for rectangular openings was derived, and it could be used as a tool to predict the burst failure of surrounding rock [40].

The evolution law of fracture field in the overlying strata has been extensively studied. Qian et al. [34] summarized the characteristics of three horizontal and three vertical zones of overburden and revealed the two-stage developing law of mining-induced fracture and the distribution characteristics of "O-shape" circle. Lin et al. [41] believed that an elliptic paraboloid zone can be formed after the coalescence between fracture fissures and separation fissures. The fractal theory was applied to the self-similarity analysis of crack distribution [42]. Taking an actual mining face with large lip as a research object, Ye et al. [43] developed an analogy simulation test system to investigate the evolution law of mininginduced crack in overburden. Liu et al. [44] quantitatively described the fractal characteristics of mining-induced fracture in overlying strata, and the results indicated coalrock dynamic disaster induced by overburden failure would occur when the fractal dimension decreases to the lowest value. Based on the secondary developed mining discontinuous deformation analysis program (MDDA), Zuo et al. [45] analysed the evolution laws of the fracture field in different combined mining stages of coal and oil shale, as shown in Figure 5. It has been found that distinct "three zones" (caving zone, fracture zone, and subsidence zone) in overlying strata will occur with coal seam mining. The stepped dislocation appears in the caving zone, and the fractured zone where the oil shale is located remains continuous overall. The oil shale is re-compacted and its strength begins to increase gradually after the coal bed is mined for a certain distance.

The coupling behaviour of mining-induced stress field, energy field, and fracture field has also been studied. By using theoretical analysis, numerical test, and physical simulation, Yan et al. [46] studied the spatiotemporal coupling law and disaster-causing mechanism of multiphysics in the deep stope. The mechanism of multiphysics coupling disasters is as follows: mining disturbance $\longrightarrow$ stress redistribution $\longrightarrow$ stress concentration (energy accumulation) $\longrightarrow$ fracture development $\longrightarrow$ energy dissipation $\longrightarrow$ stress transfer $\longrightarrow$ stress redistribution $\longrightarrow$ stress concentration again (energy 


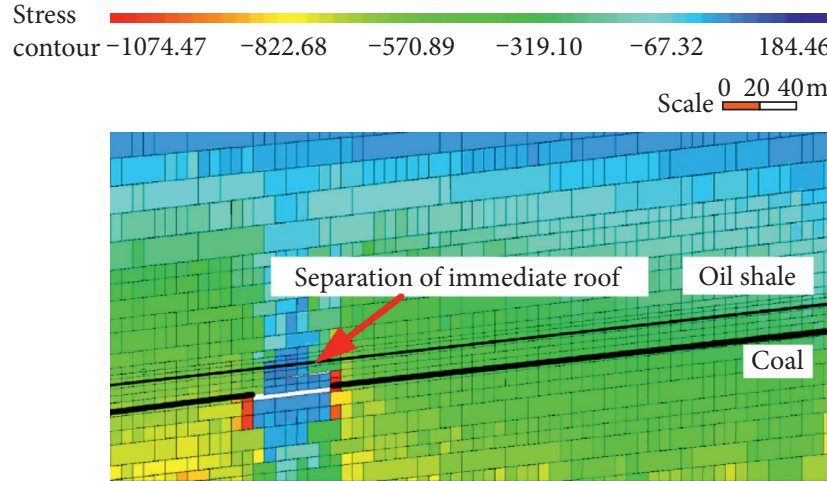

(a)
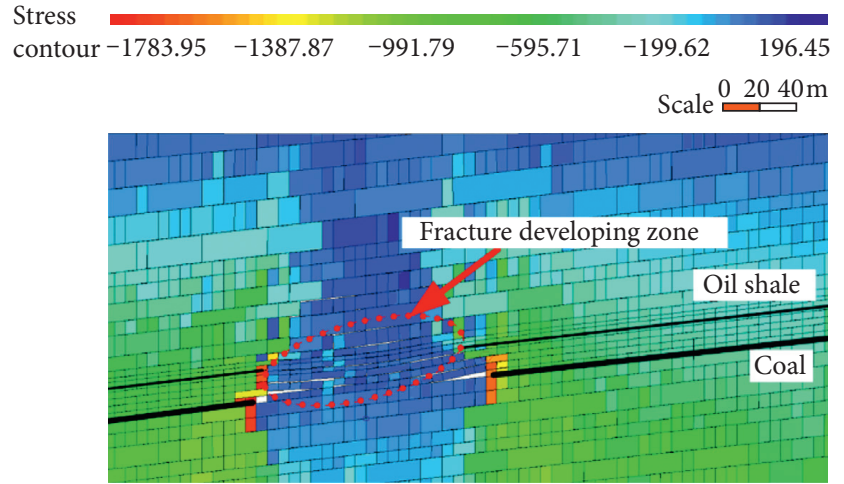

(c)
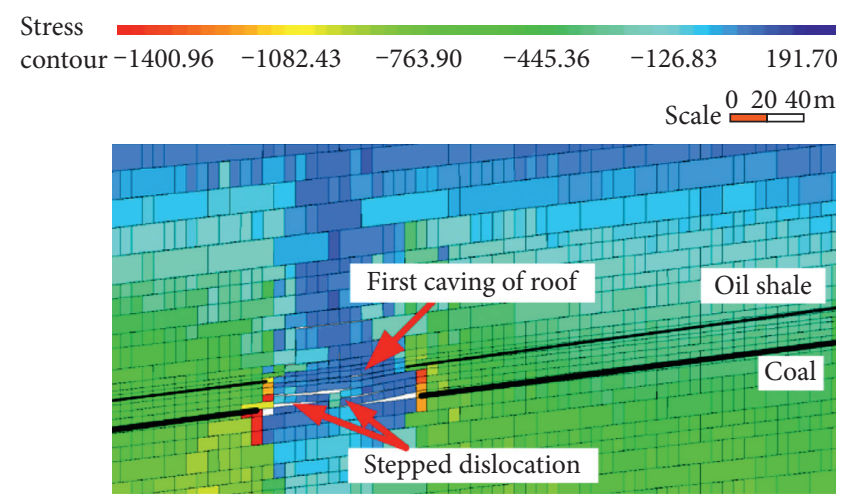

(b)

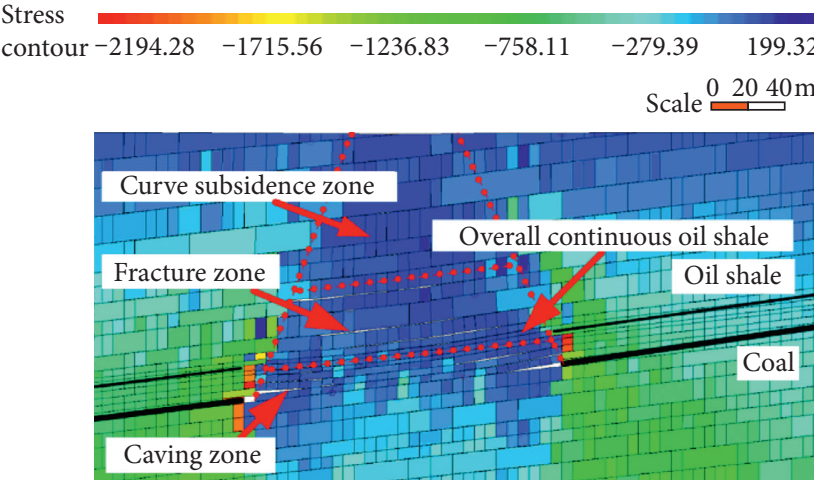

(d)

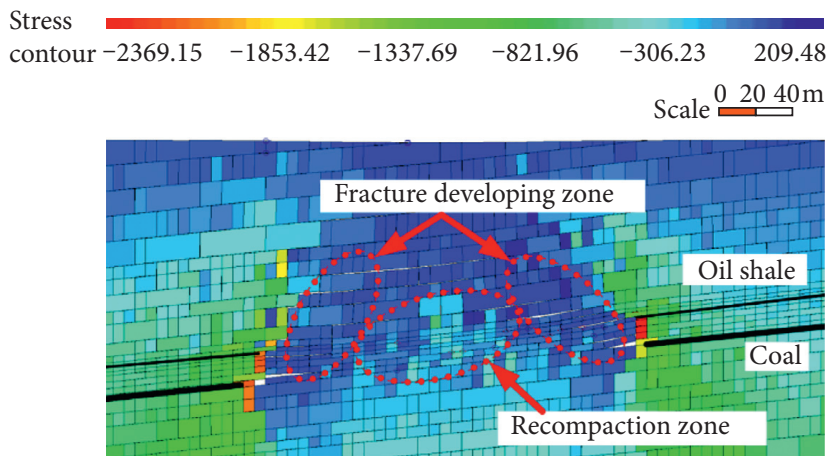

(e)

Figure 5: Evolution laws of fracture and stress fields at different advancing stages of coal and oil shale combined mining. (a) $25 \mathrm{~m}$. (b) $50 \mathrm{~m}$. (c) $75 \mathrm{~m}$. (d) $100 \mathrm{~m}$. (e) $125 \mathrm{~m}$.

accumulation again) $\longrightarrow$ fracture propagation $\longrightarrow$ energy dissipation $\longrightarrow \cdots \longrightarrow$ high stress concentration (high energy accumulation) $\longrightarrow$ surrounding rock breakage (instant energy release) $\longrightarrow$ dynamic disaster. It can be seen that the occurrence of dynamic disasters is the result of continuous coupling and evolution of mining-induced stress, energy, and fracture fields.

\section{Motion State of Coal and Rock Mass}

5.1. The Burst Failure Mechanism of Coal and Rock Mass. Li [47] considered that the rock burst in coal mine can be simply regarded as the abrupt failure of coal and rock mass, and the research on its mechanism should clarify two basic problems, namely, the reason why coal and rock mass fail and the reason why they suddenly fail. According to the concept of Newton's second law, the unbalanced external loads on surrounding rock can produce an initial acceleration and cause excessive deformation in coal and rock mass. When the initial acceleration is overlarge, the violent failure of surrounding rock will occur. Aiming at the aforementioned two problems, scholars worldwide have conducted much research on rock burst mechanism with theoretical analysis, experimental investigation, and numerical simulation.

The early research on rock burst mechanism mainly focuses on strength theory, energy theory, stiffness theory, and burst liability theory [48-50]. Chinese scholars carried 
out independent investigations and put forward many valuable theories that suit the actual mining conditions in China. Zhang et al. [51] considered that rock burst and outburst are both the dynamic instability processes of the mechanical deformation system of coal and rock mass and proposed a united instability theory. Qi et al. [10] claimed that rock burst is induced by the abrupt sliding in coal and rock layers when the shear strength criterion is satisfied. As a result, the "three-factor" criterion of rock burst was put forward. Aiming at the dynamic disasters occurring in the fully mechanized top coal caving face of composite thick coal seam, Jiang et al. [52] discovered that the abrupt change of vertical stress near the coal seam caused by the abrupt change of horizontal stress in thick and hard strata is the main reason for the occurrence of rock burst induced by mine tremor. Pan et al. [11] distinguished the rock burst occurrence into three phases, i.e., start-up, energy transfer, and rock burst appearance, and put forward rock burst startup theory. Based on the theoretical analysis, laboratory experiment, and field test, Dou et al. [6] proposed the principle of rock burst induced by dynamic stress and static stress superposition. Nowadays, with the application of mathematical and mechanical methods, a series of achievements have been made on rock burst failure mechanism by using nonlinear dynamics, fracture mechanics, damage mechanics, fractal, chaos, catastrophe, and other theories. Vardoulakis [53] considered the burst instability of surrounding rock as structural surface instability. Xie and Pariseau [54] investigated the distribution of microseismic event during rock burst process with fractal geometry and found that the fractal dimension decreases with the development of microfracture in rock mass and reaches the minimum value just before rock burst. Dyskin and Germanovich [55] analysed the mechanism of splitting type rock burst with fracture mechanics and revealed that the cracks near coal wall continuously extend in the compressive stress concentration area and finally form thinwalled coal layer which will undergo buckle failure under mining disturbance. Qin et al. [56] studied the instability mechanism of a roof and coal pillar system by using catastrophe theory. Based on a dynamic analysis model of anchoring supporting structure, Wang et al. [57] believed that the impact resistance induced by energy release triggered serious damage to roadway.

The experimental studies of the failure mechanism of coal and rock mass have been widely carried out. A similar material with epoxy resin and proper curing agent was developed to simulate the translational rock burst [58]. Based on the frictional sliding tests on coal and rock mass, Qi et al. [59] discovered that the viscous sliding phenomenon is quite similar to the instantaneous instability of coal mass, which verifies the instability sliding mechanism of rock burst. Jiang et al. [60] investigated the structural instability of coal bump through the frictional sliding experiments on coal-rock composite samples and distinguished the failure process into three periods, namely, quiet, acceleration, and stable. A series of slip experiments with red sandstone samples were conducted to discover the threshold conditions of slip type rock burst triggered by external disturbances [61]. A great number of uniaxial compression experiments have been performed to investigate the mechanical properties of coal and rock mass [62-64]. But the actual coal seam structure is a mechanically balanced system composed of roof, coal bed, and floor, in which the stress state is constantly changing due to the mining activities. Recent studies have shown that most of the deep coal mine disasters present overall coal-rock instability failure. Zuo et al. [65-68] carried out various tests on coal-rock composite sample (see Figure 6), including uniaxial, triaxial, and cyclic loading and unloading tests, to study the failure modes, strength, and acoustic emission characteristics. Moreover, the influence of loading rate on the mechanical properties of coal-rock composite sample was studied [69]. The burst liability of coal and rock has also been widely determined around the world $[50,70,71]$. Based on a lot of burst liability tests on coal-rock composite samples, Li et al. [72] discovered that the burst liability indices based on coalrock composite model are higher than those of the pure coal model, suggesting that the composite model should be used to evaluate the coal seam burst liability. Besides, Zhao and Jiang [73] researched the relationship between the microstructure and burst liability of coal from microscopic analysis.

In terms of numerical simulation, Zubelewicz and Mróz [74] first studied the dynamic instability of rock mass with the finite element method. Tang [75] and Chen et al. [76] presented a double rock sample model to investigate rock burst mechanism and simulated the progressive damage process of surrounding rock using rock failure process analysis program (RFPA). A strike-slip model was established by the distinct element code to simulate the initial quasistatic and subsequent dynamic response of shear type rock burst [77]. Moreover, the effect of gas pressure on coal burst tendency was discussed [78]. Tan et al. [79] analysed the burst liability of coal-rock composite samples using particle flow code. Xu and Cai [80] conducted a FEM-based numerical test to analyse the strain energy released from test machines, which causes rock instability failures and delayed rock bursts.

\subsection{The Theoretical Failure Model of Coal and Rock Mass.} Currently, elastoplastic and fracture-damage models are the two theoretical models describing the nonlinear mechanical behaviour of rock. In terms of the elastoplastic model, Dafalias [81] derived two general conditions for elastoplastic coupling within the rate-independent plastic strain space. Afterwards, Han and Chen [82] established a plasticity formula in the strain space to describe the elastoplastic coupling behaviour of rock-like materials. For the jointed rock masses, Cai and Horii [83] proposed several elastoplastic constitutive models considering the joint interactions. With the method combining the strength and deformation of intact rock and joints, respectively, Wang and Huang [84] put forward a three-dimensional nonlinear model to describe the prepeak and postpeak deformation characteristics of rock mass. Several elastoplastic constitutive models were established to describe the rock strain-softening 
response in the postpeak period based on different strength criteria [85, 86]. For coal, Liu et al. [87] proposed a nonlinear model, which takes the visco-elastoplasticity into account, to characterize the creep phenomenon of soft coal. For the coal-rock composite sample, a nonlinear theoretical model, regarding rock as a hard part and coal soft part, was established to characterize its whole deformation based on natural strain and engineering strain [88]. Figure 7 depicts its whole deformation process under loading, in which the meanings of symbols are detailed in the literature. Subsequently, Zuo et al. $[89,90]$ further studied the evolution laws of cracks in coal-rock composite samples and developed an axial crack closure model (ACCM), an axial crack propagation model (ACPM), and a postpeak axial crack coalescence model, which can well describe the nonlinear characteristics of prepeak and postpeak stress-strain.

At present, the continuum damage model and microscopic damage model are two main kinds of damage models. Krajcinovic and Silva [91] and Lemaitre [92] first applied damage mechanics to rock-like materials. For the cracked rock masses, Ju [93] proposed a series of energy-based damage models to characterize the initiation and growth of microcracks. An anisotropic damage model with a microstructural damage variable was established, which provides more characterizations of microdefects in geomaterials [94]. Based on the presupposition that the microunit strength of rock complies with Weibull distribution, the elastoplastic statistical damage constitutive models of rock were developed $[95,96]$. For coal, a damage evolution model considering residual strength was proposed according to the electromagnetic radiation characteristics of coal under uniaxial compression [97]. Besides, a damage constitutive model of coal in coal-rock composite sample was presented by linking damage body with Newton body to reflect the effects of coal-rock height ratio, combination form, and lithology on the mechanical characteristics of coal [98]. In the aspect of microscopic damage model, a microcrackbased continuum damage model that combines the principal advantages of phenomenology and micromechanics was presented [99]. Zhu et al. [100] put forward the micromechanical models for anisotropic damage of brittle rocks based on homogenization techniques.

\section{Monitoring and Warning Technology for Rock Burst}

At present, rock burst monitoring methods can be distinguished as the rock mechanics method and geophysical method according to monitoring objects and principles. The rock mechanics method is mainly characterized by monitoring dynamic phenomena, stress variation, and deformation of surrounding rock. It belongs to the direct contact monitoring method and contains drilling method, borehole stress measurement, mine pressure observation, and surrounding rock deformation measurement. The drilling method is widely used because of its easy operation, but it also has the disadvantages of high risk and inability to perform real-time monitoring. According to the basic principle of the equivalent drilling method, Qu et al. [101] presented a real-time monitoring and precaution method for rock burst by analysing the relationships among drilling crumbs, support pressure, and borehole stress, while stress measurement was adopted instead of drilling crumbs as the main monitoring index. The borehole stress measurement method is also applied through measuring the relative stress of coal mass and analysing its variation trend. For the past few years, China Coal Research Institute developed a multipoint stress monitoring sensor which can achieve continuous monitoring on coal and rock stress at multiple locations with various depths. On this basis, the KJ820 online stress monitoring system connected by fiber Bragg grating has been developed, which contains stress monitoring device, data network transmission device, and display platform, as shown in Figure 8.

The geophysical method is mainly characterized by capturing the elastic wave, acoustic emission, electromagnetic wave, and other signals released by coal and rock mass [102-104]. It is regarded as the noncontact monitoring method, including the microseism method, acoustic emission method, electromagnetic radiation method, charge induction method, and seismic CT method. The microseism and acoustic emission methods are both used to monitor the vibration effect caused by coal and rock fracture. By comparison, the microseism method is adaptable for high-energy and low-frequency events, whereas the acoustic emission method suits low-energy and high-frequency events. The microseism method is widely applied to regional rock burst monitoring due to its wide monitoring range and high positioning accuracy. By contrast, the acoustic emission method has limited monitoring range and inferior positioning accuracy. However, this method is often used in working face as a supplement to the microseism method due to its sensitivity on acoustic emission signals generated by near-field coal mass fracture. The charge induction method, a monitoring method with great development prospects, is still in the stage of continuous validation and improvement through laboratory tests and field application [105]. The seismic CT method can be used to estimate the stress variation of rock mass based on the obtained seismic wave, and it is also feasible to predict large-scale rock bust risk [106]. Moreover, a methodology involving fuzzy mathematics was developed to predict rock burst by using microseismic monitoring technology [107].

Compared with rock burst monitoring methods mentioned above, real-time multiparameter monitoring is the development direction of rock burst monitoring as it considers more physical parameters. Based on the mechanisms of spontaneous type and induced type rock burst, a monitoring method that focuses on both vibration and stress fields was used to establish the "time-space-strength" monitoring system [108]. According to the principle of rock burst induced by static-dynamic loads, a rock burst prediction method that utilizes electromagnetic radiation and microseism together was proposed [109]. In recent years, China Coal Research Institute has studied the statistical classification model of hazard precursors based on the comprehensive analysis of various kinds of rock burst monitoring data. Then, the multiparameter comprehensive 


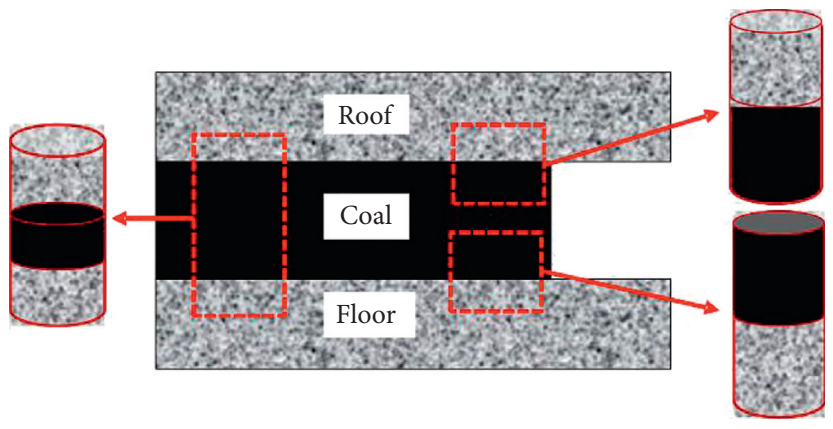

FIGURE 6: Theoretical model of coal-rock composite samples.

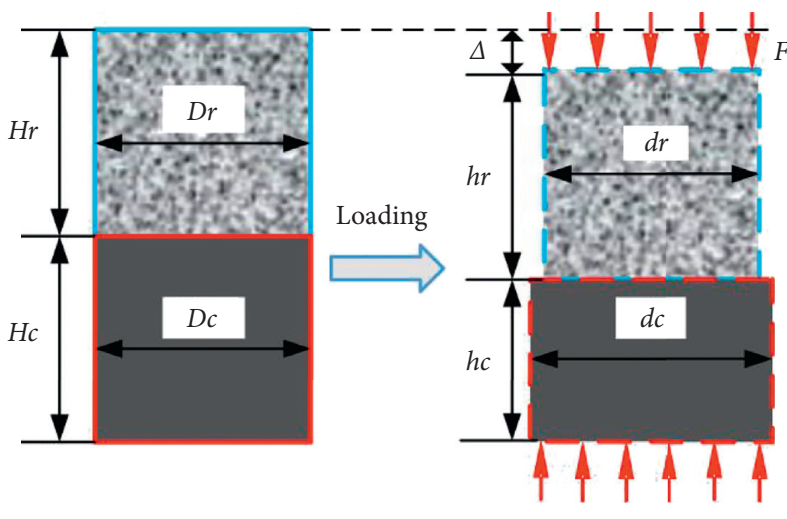

(a)

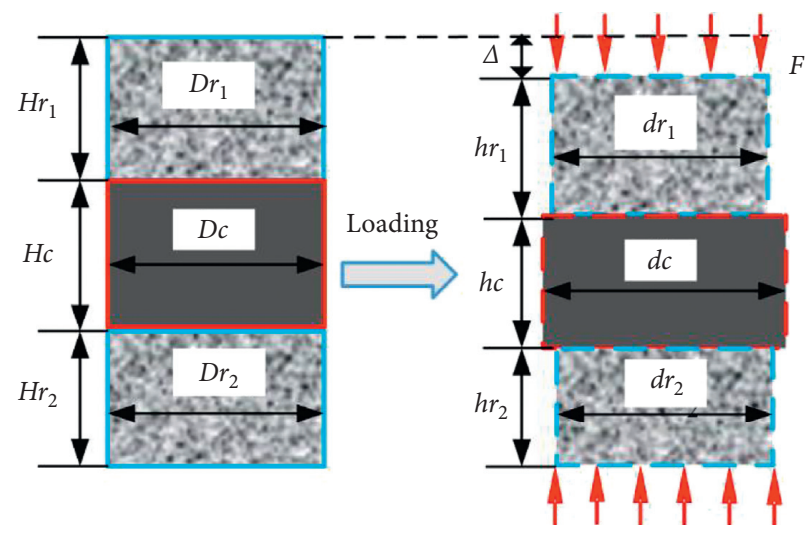

(b)

FIgURE 7: Schematic of deformation process of coal-rock composite models under loading. (a) Two-body combination model. (b) Threebody combination model.

method for rapid determination and classification of risky areas was presented by fuzzy synthetic evaluation, which can achieve integration and complete utilization of effective monitoring data. By applying data mining and data visualization technologies together, a rock burst early warning platform was established as shown in Figure 9. As a result, the integrated ground and underground mining information can support the mine production, supervision, decision, and execution departments more effectively.

\section{Prevention and Control Measures for Rock Burst}

Rock burst prevention research has been distinguished into three levels. The first level is the regional precaution study that focuses on the mining design optimisation, such as reasonable mining arrangement [110], protective layer mining, nonpillar mining, and predriven roadway. The second level is the local control study that pays attention to reducing the elastic energy accumulation by improving the properties of surrounding rock and avoiding high stress concentration. Methods related to this level include roof deep hole blasting [111], roof hydraulic fracturing, coal seam pressure relief blasting, large-diameter borehole in coal seam, floor grooving, and coal seam water injection [112]. The third level is the individual protection study that focuses on enhancing the ability to resist burst based on the improvement of current support methods such as energyabsorbing support device, i.e. D bolt [113], tension and compression-coupled yielding rock bolt [114], and new anchor bolt with constant resistance and large deformation support technology [115]. In view of the high three-dimensional geostress in a deep mine, Zuo et al. [116] presented a coordinative support technology with full space prestress truss and anchor for large cross-sectional roadway, which forms a 3D closed loading structure as shown in Figure 10.

At present, the intensity weakening theory [6] and stress control theory [117] are the two representative rock burst control mechanisms in China. The basic principle of prevention and control is to reduce stress concentration in coal and rock mass, and hence the elastic energy accumulated in surrounding rock cannot trigger rock burst. Some scholars recently put forward the classification control idea for rock burst according to the external load types, the structure forms of surrounding rock, and the actual risk level of rock burst. On this basis, Zhai et al. [3] proposed a 7-component framework for rock burst control, and it has been 


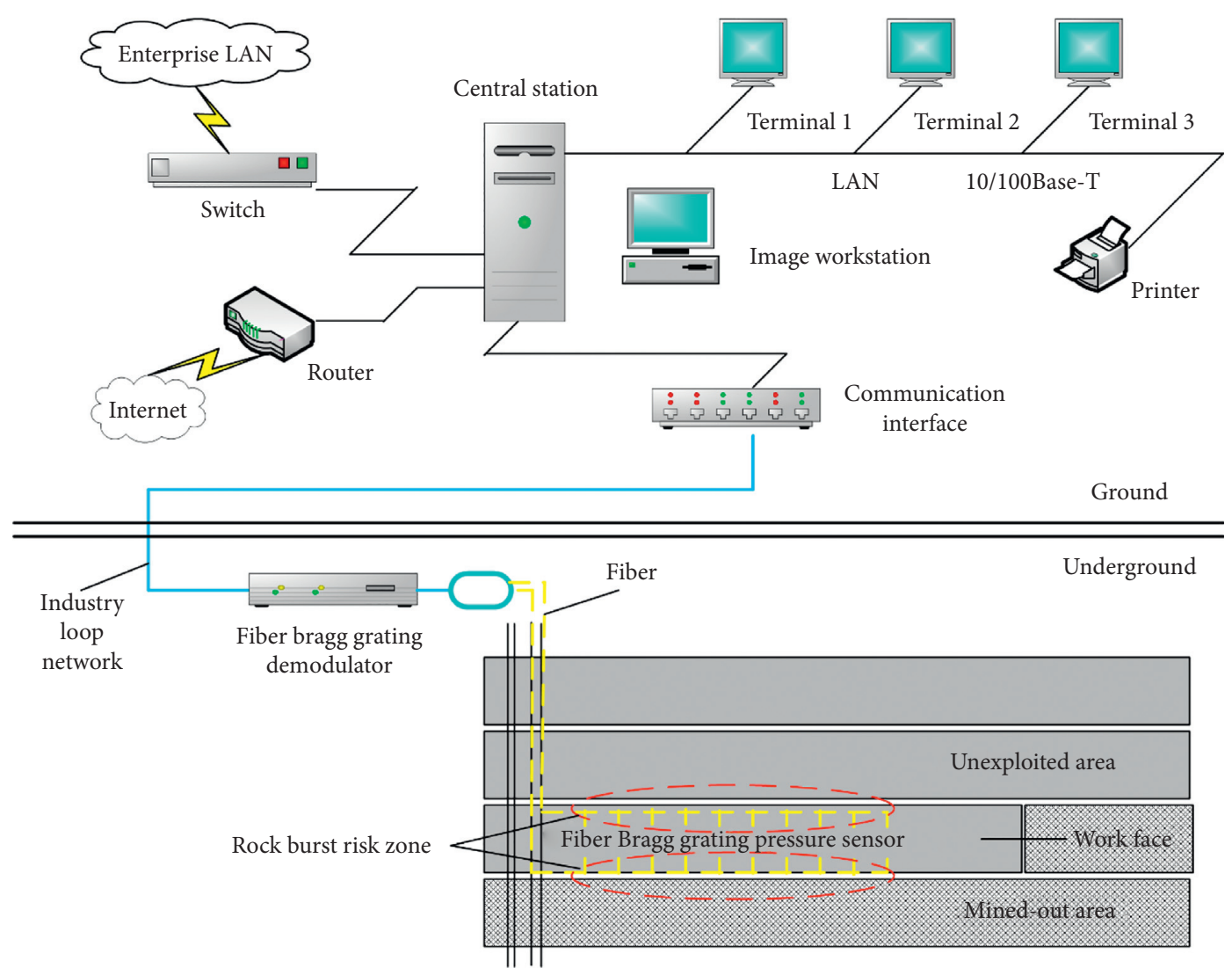

FIgURE 8: KJ820 stress online monitoring system based on fiber Bragg grating.

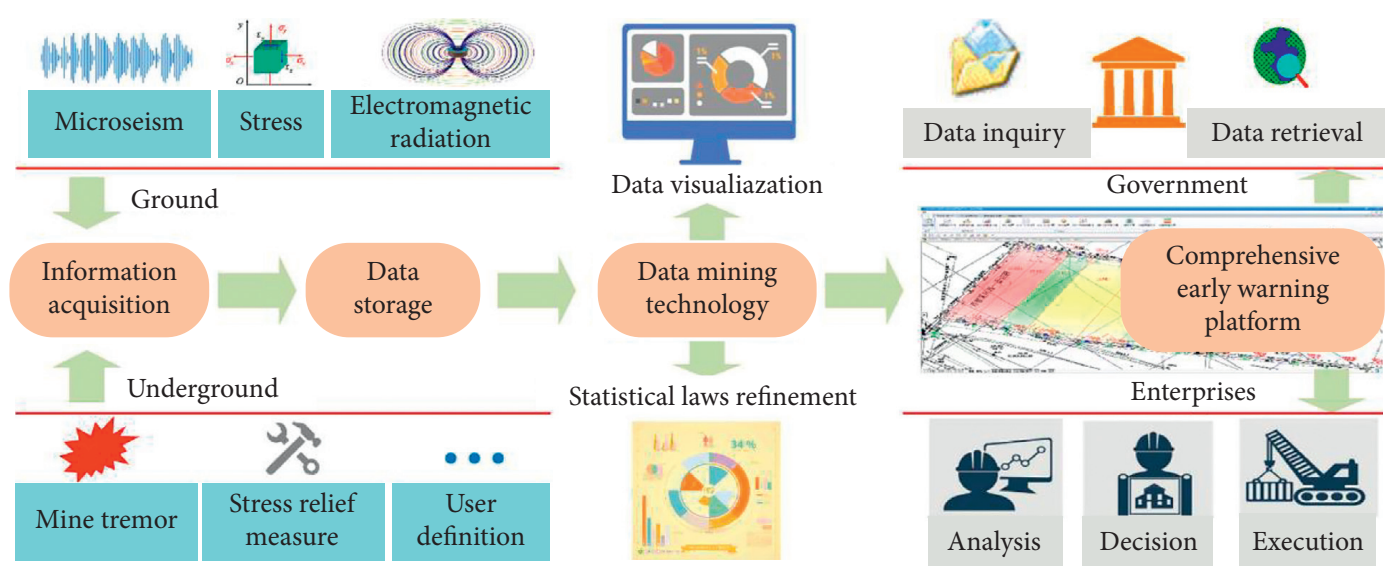

FIGURE 9: Rock burst comprehensive advance warning platform.

successfully applied in Shandong Energy Group. This framework includes classification, evaluation, danger relieving, early warning, inspection, support, and management. Previously, active control measures were only used during the mining process and the study on precautionary measures at the mining design stage was neglected. Pan et al. [118] analysed the relationship between regional mining and local rock burst start-up and proposed a regional rock burst precaution idea which dredges the concentrated static load in large-scale areas. On this basis, the regional precaution 


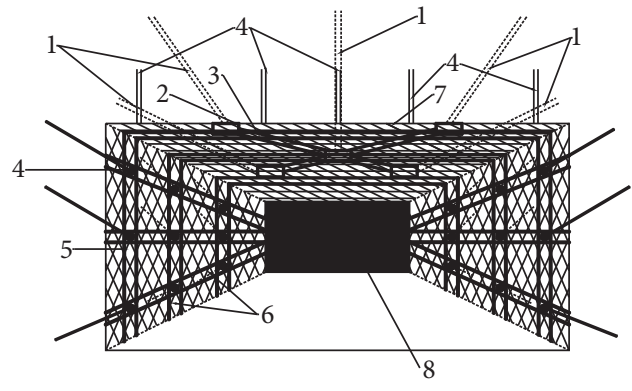

(a)

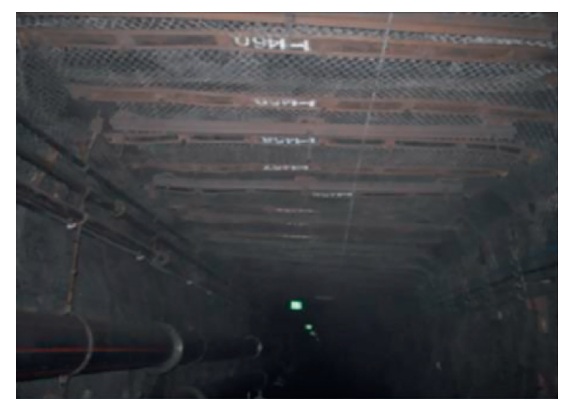

(b)

Figure 10: Full space truss and anchor coordinative support system [116]. (a) Schematic diagram. 1, cable; 2, pallet; 3, pull rod; 4, anchor; 5, steel wire mesh; 6 , steel strip; 7 , roof; 8 , coal roadway. (b) Site photo.

system of rock burst was established, and it can provide rock burst prevention guidance for the design of new mines and mining areas. Regarding rock burst control systems, Jiang et al. [119] stated eight important aspects of rock burst prevention according to mining practices and claimed that management, technical, and organization systems should be established for the rock burst control.

\section{Conclusions and Outlooks}

According to the concept of Newton's second law, the coal and rock mass in the mining area, concentrated static and dynamic loads, and dynamic instability of surrounding rock in the process of rock burst can be represented by research object, force condition, and motion state, respectively. Therefore, rock burst can be explained by the generalized Newton's second law.

The burst liability and structure factor in the "threefactor" mechanism essentially belong to the inherent property studies of the research object, and the stress factor corresponds to the force condition, which provides the theoretical foundation for the "three-factor" mechanism based on the classic mechanics.

A comprehensive rock burst research method considering research object, force condition, and motion state is proposed because most previous research studies only focused on monitoring and controlling. This research method contains five vital research components: (1) research object emphasizes detailed exploration of engineering geological bodies in the mining area and surrounding rock classification and stability evaluation; (2) force condition includes in situ stress measurement and inversion calculation before mining and the evolution analysis of mining-induced stress, fracture, and energy fields; (3) motion state focuses on the multiscale burst failure mechanism of coal and rock mass and the establishment of theoretical failure model according to the mining field; (4) real-time monitoring and warning in potentially dangerous areas during the whole mining process; and (5) reasonable prevention and control in key risk zones. This rock burst research method emphasizes the importance of investigating the geological conditions of mining areas.

At present, the ultra-high resolution seismic reflection imaging technology is fully adopted in earthquake risk assessment, which could be introduced into coal mining to carry out a relatively finer detection of geological structures. Previous studies on coal seam structure are mainly focused on the characteristics of coal or rock individually, and hence more attention should be paid to the studies on the characteristics of coal-rock composite model, such as constitutive relation, burst liability, and failure precursor. With the progress of information technology, cloud sharing technology with real-time updating support can be utilized to integrate the data of geological condition, mining disturbance, monitoring, and risk relieving feedback. Combined with big data analysis technology, real-time rock burst risk evaluation can be achieved.

\section{Data Availability}

The data supporting this review are from previously reported studies and datasets, which have been cited. The processed data are available from the corresponding authors upon request.

\section{Conflicts of Interest}

The authors declare that there are no conflicts of interest regarding the publication of this paper.

\section{Acknowledgments}

This study was supported by the Beijing Outstanding Young Scientist Program (BJJWZYJH01201911413037), National Natural Science Foundation of China (no. 41877257), Shangxi Coal Group Key Project (2018SMHKJ-A-J-03), and Yueqi Outstanding Scholar Award Program by CUMTB.

\section{References}

[1] C. Zhang, I. Canbulat, B. Hebblewhite, and C. R. Ward, "Assessing coal burst phenomena in mining and insights into directions for future research," International Journal of Coal Geology, vol. 179, pp. 28-44, 2017.

[2] L. Yuan, "Scientific conception of precision coal mining," Journal of China Coal Society, vol. 42, no. 1, pp. 1-7, 2017.

[3] M. H. Zhai, F. X. Jiang, Q. X. Qi et al., "Research and practice of rock burst classified control system," Journal of China Coal Society, vol. 42, no. 12, pp. 3116-3124, 2017. 
[4] W. D. Ortlepp and T. R. Stacey, "Rockburst mechanisms in tunnels and shafts," Tunnelling and Underground Space Technology, vol. 9, no. 1, pp. 59-65, 1994.

[5] T.-H. Ma, C.-A. Tang, S.-B. Tang et al., "Rockburst mechanism and prediction based on microseismic monitoring," International Journal of Rock Mechanics and Mining Sciences, vol. 110, pp. 177-188, 2018.

[6] L.-m. Dou, Z.-1. Mu, Z.-1. Li, A.-y. Cao, and S.-y. Gong, "Research progress of monitoring, forecasting, and prevention of rockburst in underground coal mining in China," International Journal of Coal Science \& Technology, vol. 1, no. 3, pp. 278-288, 2014.

[7] P. Konicek and P. Waclawik, "Stress changes and seismicity monitoring of hard coal longwall mining in high rockburst risk areas," Tunnelling and Underground Space Technology, vol. 81, pp. 237-251, 2018.

[8] A. T. Iannacchione and S. C. Tadolini, "Coal mine burst prevention controls," in Proceedings of the 27th International Conference on Ground Control in Mining, West Virginia University, Morgantown, WV, USA, pp. 20-28, July 2008.

[9] W.-Y. Guo, T.-B. Zhao, Y.-L. Tan, F.-H. Yu, S.-C. Hu, and F.-Q. Yang, "Progressive mitigation method of rock bursts under complicated geological conditions," International Journal of Rock Mechanics and Mining Sciences, vol. 96, pp. 11-22, 2017.

[10] Q. X. Qi, T. Q. Liu, and Y. W. Shi, "Mechanism of friction sliding destability of rock burst," Journal of Mining and Safety Engineering, vol. 12, no. 3, pp. 174-177, 1995.

[11] J. F. Pan, Y. Ning, D. B. Mao, H. Lan, T. T. Du, and Y. W. Peng, "Theory of rockburst start-up during coal mining," Chinese Journal of Rock Mechanics and Engineering, vol. 31, no. 3, pp. 586-596, 2012.

[12] Y. S. Pan, Z. H. Li, and M. T. Zhang, "Distribution, type, mechanism and prevention of rockburst in China," Chinese Journal of Rock Mechanics and Engineering, vol. 22, no. 11, pp. 1844-1851, 2003.

[13] L. M. Dou, C. G. Zhao, S. G. Yang, and X. R. Wu, Prevention and Control of Rock Burst in Coal Mine, China University of Mining and Technology Press, Xuzhou, China, 2006.

[14] Y. Jiang, Y. Zhao, H. Wang, and J. Zhu, "A review of mechanism and prevention technologies of coal bumps in China," Journal of Rock Mechanics and Geotechnical Engineering, vol. 9, no. 1, pp. 180-194, 2017.

[15] G. A. Tselentis and P. Paraskevopoulos, "Application of a high-resolution seismic investigation in a Greek coal mine," Geophysics, vol. 67, no. 1, pp. 50-59, 2002.

[16] W. Wang, X. Gao, S. Y. Li et al., "Channel wave tomography method and its application in coal mine exploration: an example from Henan Yima mining area," Chinese Journal of Geophysics, vol. 55, no. 3, pp. 1054-1062, 2012.

[17] M. H. Loke, J. E. Chambers, D. F. Rucker, O. Kuras, and P. B. Wilkinson, "Recent developments in the direct-current geoelectrical imaging method," Journal of Applied Geophysics, vol. 95, pp. 135-156, 2013.

[18] W.-y. Chen, G. Q. Xue, Y. K. Muhammad et al., "Application of short-offset TEM (SOTEM) technique in mapping waterenriched zones of coal stratum, an example from east China," Pure and Applied Geophysics, vol. 172, no. 6, pp. 1643-1651, 2015.

[19] X. Xu, S. Peng, and F. Yang, "Development of a ground penetrating radar system for large-depth disaster detection in coal mine," Journal of Applied Geophysics, vol. 158, pp. 41-47, 2018.
[20] J.-P. Zuo, S.-P. Peng, Y.-J. Li, Z.-H. Chen, and H.-P. Xie, "Investigation of Karst collapse based on 3-D seismic technique and DDA method at Xieqiao coal mine, China," International Journal of Coal Geology, vol. 78, no. 4, pp. 276-287, 2009.

[21] D. U. Deere, "Technical description of rock cores for engineering purposes," Rock Mechanics and Engineering Geology, vol. 1, no. 1, pp. 17-22, 1964.

[22] Z. T. Bieniawski, "Engineering classification of jointed rock masses," Transactions of the South African Institution of Civil Engineers, vol. 15, no. 12, pp. 335-344, 1973.

[23] N. Barton, R. Lien, and J. Lunde, "Engineering classification of rock masses for the design of tunnel support," Rock Mechanics, vol. 6, no. 4, pp. 189-236, 1974.

[24] Ministry of Water Resources of the People's Republic of China, Standard for Engineering Classification of Rock Masses (GB50218-2014), China Planning Press, Beijing, China, 2014.

[25] Ministry of Coal Industry of the People's Republic of China, Roof Stability Classification of Coalface in Gently Inclined Coal Seams (MT/T 554-1996), China Coal Industry Publishing House, Beijing, China, 1996.

[26] H. Jalalifar, S. Mojedifar, A. A. Sahebi, and H. NezamabadiPour, "Application of the adaptive neuro-fuzzy inference system for prediction of a rock engineering classification system," Computers and Geotechnics, vol. 38, no. 6, pp. 783-790, 2011.

[27] V. Saati and A. Mortazavi, "Numerical modelling of in situ stress calculation using borehole slotter test," Tunnelling and Underground Space Technology, vol. 26, no. 1, pp. 172-178, 2011.

[28] M. C. He, H. P. Xie, S. P. Peng, and Y. D. Jiang, "Study on rock mechanics in deep mining engineering," Chinese Journal of Rock Mechanics and Engineering, vol. 24, no. 16, pp. 2803-2813, 2005.

[29] C. Ljunggren, Y. Chang, T. Janson, and R. Christiansson, "An overview of rock stress measurement methods," International Journal of Rock Mechanics and Mining Sciences, vol. 40, no. 7-8, pp. 975-989, 2003.

[30] M. Cai, L. Qiao, C. Li, B. Yu, and S. Wang, "Results of in situ stress measurements and their application to mining design at five Chinese metal mines," International Journal of Rock Mechanics and Mining Sciences, vol. 37, no. 3, pp. 509-515, 2000.

[31] G. Klee, F. Rummel, and A. Williams, "Hydraulic fracturing stress measurements in Hong Kong," International Journal of Rock Mechanics and Mining Sciences, vol. 36, no. 6, pp. 731-741, 1999.

[32] H. P. Kang, X. Zhang, and L. Si, "In-situ stress measurements and stress distribution characteristics in underground coal mines in China," Engineering Geology, vol. 116, no. 3-4, pp. 333-345, 2010.

[33] S. Zhang and S. Yin, "Determination of in situ stresses and elastic parameters from hydraulic fracturing tests by geomechanics modeling and soft computing," Journal of Petroleum Science and Engineering, vol. 124, pp. 484-492, 2014.

[34] M. G. Qian, P. W. Shi, and J. L. Xu, Mining Pressure and Strata Control, China University of Mining and Technology Press, Xuzhou, China, 2nd edition, 2010.

[35] Z. Q. Song, Practical Method of Mine Pressure Control, China University of Mining and Technology Press, Xuzhou, China, 1st edition, 1988.

[36] W. Xu, E. Wang, R. Shen, D. Song, and J. Zhang, "Distribution pattern of front abutment pressure of fully- 
mechanized working face of soft coal isolated island," International Journal of Mining Science and Technology, vol. 22, no. 2, pp. 279-284, 2012.

[37] W. Yang, B.-q. Lin, Y.-a. Qu et al., "Stress evolution with time and space during mining of a coal seam," International Journal of Rock Mechanics and Mining Sciences, vol. 48, no. 7, pp. 1145-1152, 2011.

[38] X. Y. Li, N. J. Ma, Y. P. Zhong, and Q. C. Gao, "Storage and release regular of elastic energy distribution in tight roof fracturing," Chinese Journal of Rock Mechanics and Engineering, vol. 26, no. s1, pp. 2786-2793, 2007.

[39] J.-A. Wang and H. D. Park, "Comprehensive prediction of rockburst based on analysis of strain energy in rocks," Tunnelling and Underground Space Technology, vol. 16, no. 1, pp. 49-57, 2001.

[40] X. Dong, A. Karrech, H. Basarir, M. Elchalakani, and C. Qi, "Analytical solution of energy redistribution in rectangular openings upon in-situ rock mass alteration," International Journal of Rock Mechanics and Mining Sciences, vol. 106, pp. 74-83, 2018.

[41] H. F. Lin, S. G. Li, L. H. Cheng, and H. Y. Pan, "Study on the principle and technology of coal and methane simultaneous extraction based on the mining fissure elliptic parabolic zone," in Proceedings of International Conference on Computer Distributed Control and Intelligent Environmental Monitoring, pp. 1830-1834, Changsha, China, February 2011.

[42] G. M. Yu, H. P. Xie, J. F. Zhao, and L. Yang, "Fractal evolution of a crack network in overburden rock stratum," Discrete Dynamics in Nature and Society, vol. 5, Article ID 181040, 6 pages, 2000.

[43] Q. Ye, G. Wang, Z. Jia, C. Zheng, and W. Wang, "Similarity simulation of mining-crack-evolution characteristics of overburden strata in deep coal mining with large dip," Journal of Petroleum Science and Engineering, vol. 165, pp. 477-487, 2018.

[44] C. Liu, J. Xue, G. Yu, and X. Cheng, "Fractal characterization for the mining crack evolution process of overlying strata based on microseismic monitoring technology," International Journal of Mining Science and Technology, vol. 26, no. 2, pp. 295-299, 2016.

[45] J. P. Zuo, Y. J. Sun, G. H. Jiang, P.-f. Wang, W.-b. Wang, and Y. Shi, "Failure behavior and simulation analysis on coal and oil shale combined mining through ascending unloading mining method," Journal of China Coal Society, vol. 42, no. 3 , pp. 567-573, 2017.

[46] H. Yan, J. X. Zhang, Q. Zhang, X. J. Dong, and X. L. Han, "Coupling evolution mechanism of mining-induced overlying strata stress field and crack field under extremely thick igneous rock," Journal of China Coal Society, vol. 41, no. 9, pp. 2173-2179, 2016.

[47] Y. S. Li, "Rockburst mechanism and its preliminary application," Journal of China University of Mining and Technology, vol. 44, no. 3, pp. 37-43, 1985.

[48] N. G. W. Cook, "The failure of rock," International Journal of Rock Mechanics and Mining Sciences \& Geomechanics Abstracts, vol. 2, no. 4, pp. 389-403, 1965.

[49] I. M. Petukhov and A. M. Linkov, "The theory of post-failure deformations and the problem of stability in rock mechanics," International Journal of Rock Mechanics and Mining Sciences \& Geomechanics Abstracts, vol. 16, no. 2, pp. 57-76, 1979.

[50] A. Kidybinski, "Bursting liability indices of coal," International Journal of Rock Mechanics and Mining Sciences \& Geomechanics Abstracts, vol. 18, no. 4, pp. 295-304, 1981.
[51] M. T. Zhang, Z. H. Xu, Y. S. Pan, and Y. S. Zhao, "A united instability theory on coal (rock) burst and outburst," Journal of China Coal Society, vol. 16, no. 4, pp. 48-53, 1991.

[52] F. X. Jiang, P. Wang, Z. Q. Feng, and D. Z. Wang, "Mechanism, prediction and control of "rock burst induced by shock bump" kind dynamic accident in composite thickness coal," Journal of China Coal Society, vol. 34, no. 12, pp. 1605-1609, 2009.

[53] I. Vardoulakis, "Rock bursting as a surface instability phenomenon," International Journal of Rock Mechanics and Mining Sciences \& Geomechanics Abstracts, vol. 21, no. 3, pp. 137-144, 1984.

[54] H. Xie and W. G. Pariseau, "Fractal character and mechanism of rock bursts," International Journal of Rock Mechanics and Mining Sciences \& Geomechanics Abstracts, vol. 30, no. 4, pp. 343-350, 1993.

[55] A. V. Dyskin and L. N. Germanovich, "Model of rockburst caused by cracks growing near free surface," in Rockbursts and Seismicity in Mines pp. 169-174, Rotterdam, Netherlands, 1993.

[56] S. Q. Qin, J. J. Jiao, C. A. Tang, and Z. G. Li, "Instability leading to coal bumps and nonlinear evolutionary mechanisms for a coal-pillar-and-roof system," International Journal of Solids and Structures, vol. 43, no. 25-26, pp. 7407-7423, 2006.

[57] Z. Y. Wang, L. M. Dou, and G. F. Wang, "Mechanism analysis of roadway rockbursts induced by dynamic mining loading and its application," Energies, vol. 11, no. 9, Article ID 2313, 2018.

[58] W. Burgert and H. Lippmann, "Models of translatory rock bursting in coal," International Journal of Rock Mechanics and Mining Sciences \& Geomechanics Abstracts, vol. 18, no. 4, pp. 285-294, 1981.

[59] Q. X. Qi, Y. W. Shi, and T. Q. Liu, "Mechanism of instability caused by viscous sliding in rock burst," Journal of China Coal Society, vol. 22, no. 2, pp. 144-148, 1997.

[60] Y. D. Jiang, T. Wang, Y. M. Song, X. Wang, and W. Zhang, "Experimental study on the stick-slip process of coal-rock composite samples," Journal of China Coal Society, vol. 38, no. 2, pp. 177-182, 2013.

[61] S. Deng, J. Li, H. Jiang, and M. Wang, "Experimental and theoretical study of the fault slip events of rock masses around underground tunnels induced by external disturbances," Engineering Geology, vol. 233, pp. 191-199, 2018.

[62] D. W. Hobbs, "The strength and the stress-strain characteristics of coal in triaxial compression," The Journal of Geology, vol. 72, no. 2, pp. 214-231, 1964.

[63] Z. T. Bieniawski, "The effect of specimen size on compressive strength of coal," International Journal of Rock Mechanics and Mining Sciences \& Geomechanics Abstracts, vol. 5, no. 4, pp. 325-335, 1968.

[64] R. Peng, Y. Ju, J. G. Wang, H. Xie, F. Gao, and L. Mao, "Energy dissipation and release during coal failure under conventional triaxial compression," Rock Mechanics and Rock Engineering, vol. 48, no. 2, pp. 509-526, 2015.

[65] J. P. Zuo, H. P. Xie, B. B. Meng, and J. F. Liu, "Experimental research on loading-unloading behavior of coal-rock combination bodies at different stress levels," Rock and Soil Mechanics, vol. 32, no. 5, pp. 1287-1296, 2011.

[66] J. Zuo, Z. Wang, H. Zhou, J. Pei, and J. Liu, "Failure behavior of a rock-coal-rock combined body with a weak coal interlayer," International Journal of Mining Science and Technology, vol. 23, no. 6, pp. 907-912, 2013. 
[67] J. P. Zuo, Y. Chen, J. W. Zhang et al., "Failure behavior and strength characteristics of coal-rock combined body under different confining pressures," Journal of China Coal Society, vol. 41, no. 11, pp. 2706-2713, 2016.

[68] Y. Chen, J. Zuo, D. Liu, and Z. Wang, "Deformation failure characteristics of coal-rock combined body under uniaxial compression: experimental and numerical investigations," Bulletin of Engineering Geology and the Environment, vol. 78, no. 5, pp. 3449-3464, 2019.

[69] B. Huang and J. Liu, "The effect of loading rate on the behavior of samples composed of coal and rock," International Journal of Rock Mechanics and Mining Sciences, vol. 61, pp. 23-30, 2013.

[70] S. P. Singh, "Burst energy release index," Rock Mechanics and Rock Engineering, vol. 21, no. 2, pp. 149-155, 1988.

[71] X. Yang, T. Ren, L. Tan, A. Remennikov, and X. He, "Developing coal burst propensity index method for Australian coal mines," International Journal of Mining Science and Technology, vol. 28, no. 5, pp. 783-790, 2018.

[72] J. Q. Li, Q. X. Qi, and D. B. Mao, "Discussion on evaluation method of bursting liability with composite model of coal and rock," Chinese Journal of Rock Mechanics and Engineering, vol. 24, no. s1, pp. 4805-4810, 2005.

[73] Y. Zhao and Y. Jiang, "Acoustic emission and thermal infrared precursors associated with bump-prone coal failure," International Journal of Coal Geology, vol. 83, no. 1, pp. 11-20, 2010.

[74] A. Zubelewicz and Z. Mróz, "Numerical simulation of rock burst processes treated as problems of dynamic instability," Rock Mechanics and Rock Engineering, vol. 16, no. 4, pp. 253-274, 1983.

[75] C. Tang, "Numerical simulation of progressive rock failure and associated seismicity," International Journal of Rock Mechanics and Mining Sciences, vol. 34, no. 2, pp. 249-261, 1997.

[76] Z. H. Chen, C. A. Tang, and R. Q. Huang, "A double rock sample model for rockbursts," International Journal of Rock Mechanics and Mining Sciences, vol. 34, no. 6, pp. 991-1000, 1997.

[77] Z. Khademian and O. Ugur, "Computational framework for simulating rock burst in shear and compression," International Journal of Rock Mechanics and Mining Sciences, vol. 110, pp. 279-290, 2018.

[78] H. C. Zhao and R. B. Kaunda, "Numerical assessment of the influences of gas pressure on coal burst liability," Energies, vol. 11, no. 2, Article ID 260, 2018.

[79] Y. L. Tan, W. Y. Guo, Q. H. Gu, F.-H. Yu, S.-C. Hu, and Y.-C. Yin, "Research on the rockburst tendency and AE characteristics of inhomogeneous coal-rock combination bodies," Shock and Vibration, vol. 2016, Article ID 9271434, 11 pages, 2016.

[80] Y. H. Xu and M. Cai, "Influence of strain energy released from a test machine on rock failure process," Canadian Geotechnical Journal, vol. 55, no. 13, pp. 777-791, 2017.

[81] Y. F. Dafalias, "Elasto-plastic coupling within a thermodynamic strain space formulation of plasticity," International Journal of Non-linear Mechanics, vol. 12, no. 5, pp. 327-337, 1977.

[82] D. J. Han and W. F. Chen, "Strain-space plasticity formulation for hardening-softening materials with elastoplastic coupling," International Journal of Solids and Structures, vol. 22, no. 8, pp. 935-950, 1986.

[83] M. Cai and H. Horii, "A constitutive model and FEM analysis of jointed rock masses," International Journal of Rock
Mechanics and Mining Sciences \& Geomechanics Abstracts, vol. 30, no. 4, pp. 351-359, 1993.

[84] T.-T. Wang and T.-H. Huang, "A constitutive model for the deformation of a rock mass containing sets of ubiquitous joints," International Journal of Rock Mechanics and Mining Sciences, vol. 46, no. 3, pp. 521-530, 2009.

[85] S. Wang, X. Yin, H. Tang, and X. Ge, "A new approach for analyzing circular tunnel in strain-softening rock masses," International Journal of Rock Mechanics and Mining Sciences, vol. 47, no. 1, pp. 170-178, 2010.

[86] O. Pourhosseini and M. Shabanimashcool, "Development of an elasto-plastic constitutive model for intact rocks," International Journal of Rock Mechanics and Mining Sciences, vol. 66, pp. 1-12, 2014.

[87] C. Liu, F. Zhou, J. Kang, and T. Xia, "Application of a nonlinear viscoelastic-plastic rheological model of soft coal on borehole stability," Journal of Natural Gas Science and Engineering, vol. 36, pp. 1303-1311, 2016.

[88] J. P. Zuo, Y. Chen, Y. J. Sun, G. H. Jiang, and J. T. Wang, "Investigation on whole failure nonlinear model for deep coal-rock combined bodies," Journal of Mining Science and Technology, vol. 2, no. 1, pp. 17-24, 2017.

[89] J. P. Zuo, Y. Chen, H. Q. Song, and X. Wei, "Evolution of prepeak axial crack strain and nonlinear model for coal-rock combined body," Chinese Journal of Geotechnical Engineering, vol. 39, no. 9, pp. 1609-1615, 2017.

[90] J. P. Zuo, H. Q. Song, Y. Chen, and Y. H. Li, "Post-peak progressive failure characteristics and nonlinear model of coal-rock combined body," Journal of China Coal Society, vol. 43, no. 12, pp. 3265-3272, 2018.

[91] D. Krajcinovic and M. A. G. Silva, "Statistical aspects of the continuous damage theory," International Journal of Solids and Structures, vol. 18, no. 7, pp. 551-562, 1982.

[92] J. Lemaitre, "A continuous damage mechanics model for ductile fracture," Journal of Engineering Materials and Technology, vol. 107, no. 1, pp. 83-89, 1985.

[93] J. W. Ju, "On energy-based coupled elastoplastic damage theories: constitutive modeling and computational aspects," International Journal of Solids and Structures, vol. 25, no. 7, pp. 803-833, 1989.

[94] G. Swoboda and Q. Yang, “An energy-based damage model of geomaterials-I. Formulation and numerical results," International Journal of Solids and Structures, vol. 36, no. 12, pp. 1719-1734, 1999.

[95] W.-g. Cao, X. Li, and H. Zhao, "Damage constitutive model for strain-softening rock based on normal distribution and its parameter determination," Journal of Central South University of Technology, vol. 14, no. 5, pp. 719-724, 2007.

[96] J. Deng and D. Gu, "On a statistical damage constitutive model for rock materials," Computers \& Geosciences, vol. 37, no. 2, pp. 122-128, 2011.

[97] P. Jin, E. Wang, X. Liu, N. Huang, and S. Wang, "Damage evolution law of coal-rock under uniaxial compression based on the electromagnetic radiation characteristics," International Journal of Mining Science and Technology, vol. 23, no. 2, pp. 213-219, 2013.

[98] X. S. Liu, Y. L. Tan, J. G. Ning, Y. W. Lu, and Q. H. Gu, "Mechanical properties and damage constitutive model of coal in coal-rock combined body," International Journal of Rock Mechanics and Mining Sciences, vol. 110, pp. 140-150, 2018.

[99] J. F. Shao and J. W. Rudnicki, "A microcrack-based continuous damage model for brittle geomaterials," Mechanics of Materials, vol. 32, no. 10, pp. 607-619, 2000. 
[100] Q. Zhu, D. Kondo, J. Shao, and V. Pensee, "Micromechanical modelling of anisotropic damage in brittle rocks and application," International Journal of Rock Mechanics and Mining Sciences, vol. 45, no. 4, pp. 467-477, 2008.

[101] X. C. Qu, F. X. Jiang, Z. X. Yu, and H. Y. Ju, "Rockburst monitoring and precaution technology based on equivalent drilling research and its applications," Chinese Journal of Rock Mechanics and Engineering, vol. 30, no. 11, pp. 23462351, 2011.

[102] C.-P. Lu, L.-M. Dou, B. Liu, Y.-S. Xie, and H.-S. Liu, "Microseismic low-frequency precursor effect of bursting failure of coal and rock," Journal of Applied Geophysics, vol. 79, pp. 55-63, 2012.

[103] M. C. He, J. L. Miao, and J. L. Feng, "Rock burst process of limestone and its acoustic emission characteristics under true-triaxial unloading conditions," International Journal of Rock Mechanics and Mining Sciences, vol. 47, no. 2, pp. 286-298, 2010.

[104] E. Wang, X. He, X. Liu, and W. Xu, "Comprehensive monitoring technique based on electromagnetic radiation and its applications to mine pressure," Safety Science, vol. 50, no. 4, pp. 885-893, 2012.

[105] Y. S. Pan, H. Luo, and Y. F. Zhao, "Application of charge induction monitoring technology of mine dynamic disasters," Coal Science and Technology, vol. 41, no. 9, pp. 29-33, 2013.

[106] W. Cai, L. Dou, A. Cao, S. Gong, and Z. Li, "Application of seismic velocity tomography in underground coal mines: a case study of Yima mining area, Henan, China," Journal of Applied Geophysics, vol. 109, pp. 140-149, 2014.

[107] W. Cai, L. Dou, M. Zhang, W. Cao, J.-Q. Shi, and L. Feng, "A fuzzy comprehensive evaluation methodology for rock burst forecasting using microseismic monitoring," Tunnelling and Underground Space Technology, vol. 80, pp. 232-245, 2018.

[108] F. X. Jiang, X. C. Qu, Z. X. Yu, and C. W. Wang, "Real time monitoring and measuring early warning technology and development of mine pressure bumping," Coal Science and Technology, vol. 39, no. 2, pp. 59-64, 2011.

[109] H. He, L. Dou, S. Gong, J. He, Y. Zheng, and X. Zhang, "Microseismic and electromagnetic coupling method for coal bump risk assessment based on dynamic static energy principles," Safety Science, vol. 114, pp. 30-39, 2019.

[110] H. G. Ji, H. S. Ma, J. A. Wang, Y. H. Zhang, and H. Cao, "Mining disturbance effect and mining arrangements analysis of near-fault mining in high tectonic stress region," Safety Science, vol. 50, no. 4, pp. 649-654, 2012.

[111] P. Konicek, K. Soucek, L. Stas, and R. Singh, "Long-hole destress blasting for rockburst control during deep underground coal mining," International Journal of Rock Mechanics and Mining Sciences, vol. 61, pp. 141-153, 2013.

[112] X. F. Liu, G. Xu, C. Zhang et al., "Time effect of water injection on the mechanical properties of coal and its application in rockburst prevention in mining," Energies, vol. 10, no. 11, Article ID 1783, 2017.

[113] C. C. Li, "A new energy-absorbing bolt for rock support in high stress rock masses," International Journal of Rock Mechanics and Mining Sciences, vol. 47, no. 3, pp. 396-404, 2010.

[114] X. Wu, Y. Jiang, G. Wang, B. Gong, Z. Guan, and T. Deng, "Performance of a new yielding rock bolt under pull and shear loading conditions," Rock Mechanics and Rock Engineering, vol. 52, no. 9, pp. 3401-3412, 2019.

[115] M. He, W. Gong, J. Wang et al., "Development of a novel energy-absorbing bolt with extraordinarily large elongation and constant resistance," International Journal of Rock Mechanics and Mining Sciences, vol. 67, pp. 29-42, 2014.

[116] J. Zuo, J. Wang, and Y. Jiang, "Macro/meso failure behavior of surrounding rock in deep roadway and its control technology," International Journal of Coal Science \& Technology, vol. 6, no. 3, pp. 301-319, 2019.

[117] Q. X. Qi, X. L. Li, and S. K. Zhao, "Theory and practices on stress control of mine pressure bumping," Coal Science and Technology, vol. 41, no. 6, pp. 1-5, 2013.

[118] J. F. Pan, Y. Ning, T. T. Du et al., "The theory and system for preventing rock burst in large-scale areas," Journal of China Coal Society, vol. 37, no. 11, pp. 1803-1809, 2012.

[119] F. X. Jiang, Q. D. Wei, S. L. Yao, C. W. Wang, and X. C. Qu, "Key theory and technical analysis on mine pressure bumping prevention and control," Coal Science and Technology, vol. 41, no. 6, pp. 6-9, 2013. 